\title{
Effects of Acute Hypercapnia on Maternal and Fetal Vasopressin and Catecholamine Release ${ }^{1}$
}

\author{
DANIEL J. FAUCHER, ${ }^{2}$ ABBOT R. LAPTOOK. JOHN C. PORTER, AND \\ CHARLES R. ROSENFELD \\ Departments of Pediatrics, Obstetrics and Gynecology, and Physiology. The University of Texas Southwestern \\ Medical Center at Dallas, Dallas, Texas 75235
}

\begin{abstract}
Although fetal asphyxia, i.e. hypoxemia, acidosis, and hypercapnia, increases plasma arginine vasopressin (AVP) >40-fold, hypoxemia and metabolic acidosis occurring independently cause only 5 -fold and 2 -fold increases, respectively. To determine the effects of hypercapnia on AVP release, we examined the effects of acute hypercapnia on AVP secretion in six pregnant sheep and their fetuses at $135 \pm 4 \mathrm{~d}(x \pm \mathrm{SD})$, exposing the ewe successively to room air, $30 \% \mathrm{O}_{2}, 30 \% \mathrm{O}_{2}$ plus $10 \% \mathrm{CO}_{2}$, $30 \% \mathrm{O}_{2}$, and room air, and monitoring uterine blood flow, as well as maternal and fetal mean arterial pressure, heart rate, arterial blood gases, and plasma AVP and catecholamines. Oxygen exposure had no effect on the ewe or fetus. During $\mathrm{O}_{2}$ plus $\mathrm{CO}_{2}$ exposure, the ewes and fetuses developed hypercapnia in the absence of hypoxia, arterial $\mathrm{CO}_{2}$ tension increasing to $8.38 \pm 0.87 \mathrm{kPa}(62.9 \pm 6.5 \mathrm{~mm} \mathrm{Hg})$ and $10.0 \pm 0.61 \mathrm{kPa}(75.2 \pm 4.6 \mathrm{~mm} \mathrm{Hg})(p<0.001)$, respectively, at $30 \mathrm{~min}$ of exposure. Although fetal heart rate and mean arterial pressure were unchanged, maternal values rose 61 and $30 \%(p<0.001)$, respectively. At 30 min of $\mathrm{O}_{2}+\mathrm{CO}_{2}$ exposure, maternal norepinephrine increased from $2.23 \pm 0.74$ to $8.52 \pm 3.97 \mathrm{nmol} / \mathrm{L}(p=0.15)$ and fetal epinephrine increased from $0.27 \pm 0.10$ to 2.271 $\pm 0.90 \mathrm{nmol} / \mathrm{L}(p=0.01)$; plasma AVP was not significantly increased in the ewe or fetus, although levels rose from $\sim 45$ to $127 \pm 48$ and $137 \pm 64 \mathrm{pmol} / \mathrm{L}(p=0.10)$, respectively. Hypercapnia alone is not a major determinant of AVP secretion in the mother or fetus; thus, the marked rise in fetal AVP secretion observed during asphyxial insults may reflect interaction between the effects of hypercapnia and hypoxemia. (Pediatr Res 30: 368-374, 1991)
\end{abstract}

Abbreviations

MAP, mean arterial pressure

E, epinephrine

$\mathrm{NE}$, norepinephrine

$\mathrm{PaO}_{2}$, arterial $\mathrm{O}_{2}$ tension

$\mathrm{PaCO}_{2}$, arterial $\mathrm{CO}_{2}$ tension

ANOVA, analysis of variance

$\mathrm{pH}_{\mathrm{a}}$, arterial $\mathrm{pH}$
Alterations in the homeostatic milieu trigger a complex series of events that serve to protect the individual organism against environmental insults. Asphyxia, i.e. the simultaneous occurrence of hypoxemia, acidosis, and hypercapnia, is a striking illustration of an intense "stress," and subsequent adaptive responses reflect a complex interaction of factors related to the metabolic, neuroendocrine, and cardiovascular systems. Although these responses have been examined in adult animals of several species (1-6), the ontogeny of these responses during fetal development is not fully understood.

In fetal sheep the response to stress has been characterized by increased secretion of AVP and adrenal catecholamines (7). By using the fetal sheep as a model, we and others $(5,8-12)$ have observed that fetal asphyxia, regardless of method of induction, results in substantial increases in plasma AVP concentrations, i.e. $>40$-fold rises over baseline levels. In contrast, we have shown (11) that during moderate fetal hypoxemia, i.e. a $45 \%$ decrease in $\mathrm{PaO}_{2}$ without alterations in either arterial $\mathrm{pH}$ or $\mathrm{PCO}_{2}$, plasma levels of AVP rose only modestly (5-fold over baseline values). Furthermore, induction of marked metabolic acidemia had little effect on fetal AVP secretion, i.e. only a 2 -fold rise over baseline levels (13). Because neither hypoxemia alone nor pure metabolic acidosis resulted in the substantial increase in plasma AVP seen during fetal asphyxia, the role of hypercapnia in fetal secretion of AVP, as well as the interaction of these variables, remained to be elucidated.

Catecholamines are also released during asphyxia. Rose et al. (14) demonstrated that acute hypercapnic acidosis resulted in increased circulating levels of both $\mathrm{E}$ and $\mathrm{NE}$ in adult dogs. However, NE was the predominant catecholamine released, especially when hypercapnia was combined with hypoxemia. They suggested that the major source of NE was the sympathetic nerve terminals. They also observed an increase in MAP and heart rate in response to hypercapnia. No one, to our knowledge, has addressed the effects of acute hypercapnia on circulating catecholamines in a fetal animal. Moreover, the relationship between plasma levels of these hormones and cardiovascular responses during hypercapnia has not been examined in the fetus.

Therefore, the purpose of the study presented here was to determine the effects of acute hypercapnia on fetal secretion of AVP, dopamine, NE, and $\mathrm{E}$, to examine the concomitant fetal hemodynamic responses, and to compare these alterations with those occurring simultaneously in the pregnant ewe.

\section{MATERIALS AND METHODS}

Animal preparation. Pregnant sheep $(n=6)$ of mixed Western breed bearing singleton fetuses were used in these experiments. Studies $(n=8)$ were performed at $135 \pm 4(x \pm$ SD) d of gestation (term, $\sim 145 \mathrm{~d}$ ). The surgical preparation has been described previously $(11,15)$. In brief, animals were fasted $24 \mathrm{~h}$ before surgery, which was performed at 124 to $126 \mathrm{~d}$ of gestation. After spinal anesthesia with hyperbaric lidocaine $(12 \mathrm{mg})$, i.v. pentobarbital $(\sim 15 \mathrm{mg} / \mathrm{kg})$ was administered as needed. While em-
Correspondence: Charles R. Rosenfeld, M.D., Department of Pediatrics, University of Texas Southwestern Medical Center, 5323 Harry Hines Blvd., Dallas, TX 75235-9063.

Supported by NIH Grants HD-08783, HD-20720, JD-1 1149, and DK-01237.

'Presented in part at the annual meeting of the Endocrine Society, Baltimore, MD, June 1985.

${ }^{2}$ Dr. Faucher was a postdoctoral Fellow in the Division of Neonatal-Perinatal Medicine from July 1, 1983 to June 30,1986 and is presently at McGill University, Montreal, Canada. 
ploying sterile procedures, the maternal abdomen was opened, the pregnant uterus was delivered, and a fetal hindlimb was brought out through a uterine incision. Polyvinyl catheters were implanted into a fetal femoral artery $(7.5 \mathrm{~cm})$ and vein $(15 \mathrm{~cm})$. The fetal hindlimb was returned to the amniotic sac, an amniotic catheter was inserted, and the uterus was closed with a double layer of sutures. The uterus was then returned to the maternal abdomen, and electromagnetic flow probes (Micron Instruments Inc., Los Angeles, CA) were implanted around both main uterine arteries proximal to their bifurcation. The fetal catheters and flow probe leads were brought out of the maternal abdomen through a stab wound in the fascia, and the abdominal incision was closed. Polyvinyl catheters were implanted in both maternal femoral arteries $(15 \mathrm{~cm})$ and veins $(20$ to $25 \mathrm{~cm})$. All catheters were filled with heparinized saline, closed with sterile pins, and brought out to the maternal flank with the flow probe leads via a s.c. tunnel, where they were maintained in a canvas pouch attached to the skin with steel pins. Pregnant animals received intramuscular mezlocillin $(0.5 \mathrm{~g})$ and penicillin $(600000 \mathrm{U})$ on the day of surgery and the 2 following days. Mezlocillin $(50 \mathrm{mg}$ ) was also instilled in the amniotic sac at surgery and every other day thereafter. After surgery, all animals were maintained in individual stalls in the laboratory and had free access to water and food (Purina Commercial Creep Chow II, G; Ralston-Purina Co., St. Louis, MO). Studies were performed at least $5 \mathrm{~d}$ postoperatively. Fetal sheep with abnormal blood gases or $\mathrm{pH}$ were not studied.

Experimental protocol. Acute hypercapnia was induced in pregnant ewes and their fetuses by sequentially exposing the ewe to the following gas mixtures: room air for $30 \mathrm{~min}, 30 \% \mathrm{O}_{2}$ for $30 \mathrm{~min}, 30 \% \mathrm{O}_{2}$ plus $10 \% \mathrm{CO}_{2}$ for $30 \mathrm{~min}, 30 \% \mathrm{O}_{2}$ for $30 \mathrm{~min}$, and room air for $60 \mathrm{~min}$. To obtain changes in inspired $\mathrm{O}_{2}$ and $\mathrm{CO}_{2}$, a plastic bag connected to a gas blender was loosely placed over the head of the ewe at the end of the initial room air period and the appropriate gas mixture was administered at $\sim 10 \mathrm{~L} /$ min. As previously reported, this procedure was well tolerated in all animals (11). In preliminary experiments, we observed that some ewes developed acute hypoxemia and metabolic acidosis in conjunction with respiratory acidosis; therefore, to prevent fetal and/or maternal hypoxemia as a confounding variable, we administered $30 \% \mathrm{O}_{2}$ to the ewe, establishing control room air and hyperoxia periods both before and after each exposure to $\mathrm{CO}_{2}$. This protocol was approved by the Institutional Review Board for Animal Research. Two animals were studied twice and were allowed 2 to $4 \mathrm{~d}$ between experiments. There was no gestational age effect noted in these experiments.

MAP in the lower abdominal aorta of the ewe and fetus was continuously monitored with pressure transducers (model 4-3271019; Bell and Howell, Pasadena, CA), and the output was recorded by means of a two-channel pen recorder (model 220; Brush Instruments, Div. Clevite Corp., Cleveland, OH). Intraamniotic pressure was recorded with another recorder electronically integrated with the first; the reported values for MAP are corrected for amniotic pressure. Heart rates were obtained at intervals from a direct recording of the phasic signal. Maternal respiratory rates were also obtained at the same intervals from direct observation. Uterine blood flow was monitored continuously with square-wave electromagnetic flowmeters (model RC1000; Micron Instruments, Los Angeles, CA) and was recorded by means of another two-channel recorder, which also was electronically integrated. Results are presented as total uterine blood flow.

Heparinized blood was obtained from the fetal and maternal femoral artery catheters for measurements of blood gases and $\mathrm{pH}(0.5 \mathrm{~mL})$, hematocrit $(0.2 \mathrm{~mL}), \mathrm{AVP}(2.0 \mathrm{~mL})$, and catecholamines $(1.0 \mathrm{~mL})$. Samples were collected at $15 \mathrm{~min}$ in room air, at 10 and $20 \mathrm{~min}$ in $30 \% \mathrm{O}_{2}$, at 10 -min intervals in $30 \% \mathrm{O}_{2}$ plus $\mathrm{CO}_{2}$, at 15 and $30 \mathrm{~min}$ in $30 \% \mathrm{O}_{2}$ after the end of $\mathrm{CO}_{2}$ exposure, and then at $30 \mathrm{~min}, 60 \mathrm{~min}$, and $20 \mathrm{~h}$ in room air Additional blood for measurement of AVP also was obtained
7.5 min after the end of $\mathrm{CO}_{2}$ exposure. Each sample of fetal blood collected for AVP and catecholamine measurements was centrifuged immediately, the plasma was removed, and the erythrocytes were resuspended in a volume of sterile isotonic saline equal to the plasma volume and reinfused into the fetus in the manner previously reported (15). This procedure has been shown to have no effect on AVP secretion (13). Maternal blood was handled similarly, but red cells were not reinfused. Fetal $(0.5$ $\mathrm{mL})$ and maternal $(0.5 \mathrm{~mL})$ plasma osmolalities were measured at each of these times in the first four experiments. Fetal plasma lactate levels $(0.4 \mathrm{~mL})$ were determined in two initial experiments.

Samples of amniotic fluid $(2 \mathrm{~mL})$ were collected at $15 \mathrm{~min}$ in room air, at $20 \mathrm{~min}$ in $\mathrm{O}_{2}$, at 10 -min intervals in $\mathrm{CO}_{2}$ plus $\mathrm{O}_{2}$, at 15 and $30 \mathrm{~min}$ in $\mathrm{O}_{2}$ after ending $\mathrm{CO}_{2}$, and at $30 \mathrm{~min}, 60 \mathrm{~min}$, and $20 \mathrm{~h}$ in room air for measurement of AVP.

Assays. Arterial blood samples for blood gases, $\mathrm{pH}$, and hematocrit were collected in $1.0-\mathrm{mL}$ heparinized syringes and were kept on ice until analyzed. The blood gases and $\mathrm{pH}$ were measured with a $\mathrm{pH}$ /gas analyzer (model 113 ; Instrumentation Laboratory, Lexington, MA). The hematocrit was measured on these samples by the micro-method of Wintrobe. Plasma osmolality was measured by freezing-point depression with an automatic osmometer. Lactic acid concentrations were determined by using a lactate dehydrogenase enzymatic assay on plasma $(200 \mu \mathrm{L})$ after deproteinization with $8 \%$ perchloric acid.

Blood samples for measurement of AVP were collected in chilled heparinized syringes and were immediately transferred to sterile plastic centrifuge tubes. After centrifugation at $10000 \times$ $g$ for $60 \mathrm{~s}$ in a Beckman microfuge, the plasma was removed, frozen immediately on dry ice, and stored at $-20^{\circ} \mathrm{C}$ until the time of assay. Plasma AVP was measured by RIA with rabbit antiserum R-71. The production of antiserum R-71 and the validation of this RIA have been described by Skowsky et al. (16). At the time of assay, the samples were thawed and acidified ( $\mathrm{pH} 2.0$ ) by the addition of $0.1 \mathrm{~mL}$ of $1 \mathrm{~N} \mathrm{HCl}$ and AVP was extracted from the plasma by the methods of Crofton et al. (17) with $\mathrm{C}_{18}$ Sep Pak cartridges (Waters Associates, Milford, MA). The recovery of AVP is $97 \pm 2.0 \%$. The extract was evaporated to dryness, and the residue was resuspended in $400 \mu \mathrm{L}$ of assay buffer. The RIA for AVP in our laboratory has been described (11). The sensitivity of the assay is $18 \mathrm{pmol} / \mathrm{L}$.

Blood samples for measurements of catecholamines were centrifuged at $10000 \times g$ for $1 \mathrm{~min}$, and the plasma was mixed with an equal volume of $0.6 \mathrm{M}$ perchloric acid containing $0.1 \%$ EDTA. The supernatant was stored at $-20^{\circ} \mathrm{C}$ until the time of assay for measurement of dopamine, NE, and E. Catecholamines were quantified by the radioenzymatic assay of Ben-Jonathan and Porter (18). This assay is linear from 0 to $5 \mu \mathrm{g}$ for each catecholamine and has a sensitivity of 10 to $30 \mathrm{pg}$.

Data analysis. Repeated measures ANOVA was used to analyze changes over time; when significance was observed with an $F$ value corresponding with $p<0.05$, the data were further analyzed by Duncan's multiple range test for each variable and/ or paired $t$ test. Regression lines were obtained by the leastsquares method. These analyses were performed by using the SAS system (SAS Institute Inc., Cary, NC) on a VAX computer. The data are presented as means and one SEM unless otherwise specified.

\section{RESULTS}

Respiratory and metabolic alterations. Baseline data for maternal and fetal (Table 1) arterial blood gases, $\mathrm{pH}$, and hematocrit are similar to data previously reported from our laboratory (11, 13, 19). Maternal $\mathrm{PaO}_{2}$ increased significantly at $10 \mathrm{~min}$ of $\mathrm{O}_{2}$ exposure (Fig. 1) and remained elevated throughout $\mathrm{CO}_{2}$ exposure, returning to control levels after the animals were allowed to breathe room air. By $10 \mathrm{~min}$ of $\mathrm{CO}_{2}$ inhalation, the ewes developed significant respiratory acidosis $\left[\mathrm{PaCO}_{2}=7.06 \pm 1.47\right.$ 
Table 1. Baseline maternal and fetal data $(n=8)^{*}$

\begin{tabular}{|c|c|c|}
\hline & Maternal & Fetal \\
\hline Heart rate (beats/min) & $94 \pm 6.0$ & $157 \pm 5.4$ \\
\hline $\mathrm{MAP}(\mathrm{kPa})$ & $10.8 \pm 0.32(81 \pm 2.4)$ & $6.13 \pm 0.17(46 \pm 1.3)$ \\
\hline Respiratory rate (breaths/min) & $82 \pm 5.9$ & \\
\hline Uterine blood flow (mL/min) & $1049 \pm 226$ & \\
\hline \multicolumn{3}{|l|}{ Arterial blood gases } \\
\hline $\mathrm{PaO}_{2}(\mathrm{kPa})$ & $13.6 \pm 0.48(102 \pm 3.6)$ & $2.27 \pm 0.12(17 \pm 0.9)$ \\
\hline $\mathrm{PaCO}_{2}(\mathrm{kPa})$ & $4.13 \pm 0.08(31 \pm 0.6)$ & $5.60 \pm 0.15(42 \pm 1.1)$ \\
\hline $\mathrm{pH}$ & $7.44 \pm 0.02$ & $7.36 \pm 0.02$ \\
\hline Hematocrit & $27.6 \pm 0.8$ & $31.0 \pm 0.55$ \\
\hline
\end{tabular}

* Values presented are means \pm SEM. Values in parentheses are $\mathrm{mm} \mathrm{Hg}$.

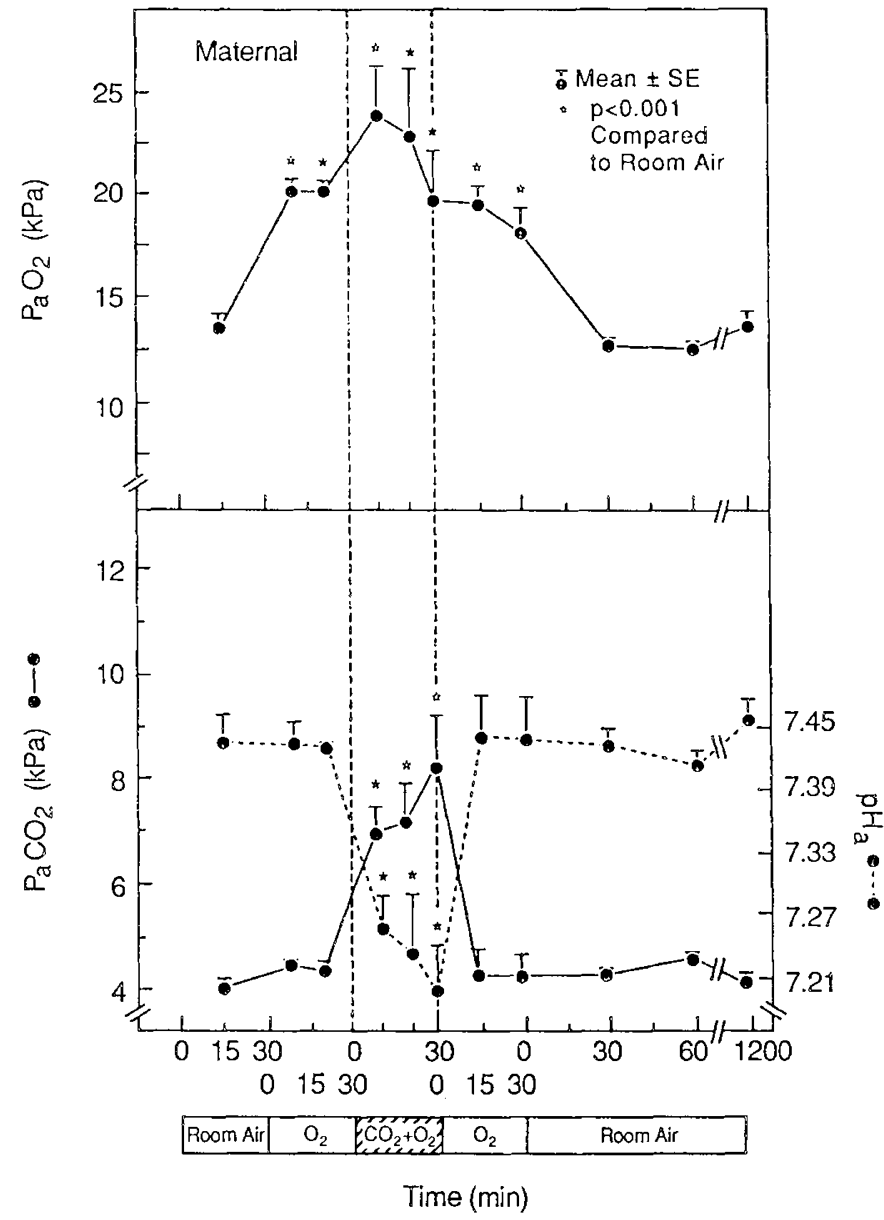

Fig. 1. Changes in maternal arterial blood gases and $\mathrm{pH}$ during successive gas exposures $(n=8)$. Analysis is by ANOVA.

$\mathrm{kPa}(53 \pm 11 \mathrm{~mm} \mathrm{Hg}) ; p<0.001]$, which persisted throughout $\mathrm{CO}_{2}$ exposure; within $15 \mathrm{~min}$ after ending $\mathrm{CO}_{2}$ inhalation, both $\mathrm{PaCO}_{2}$ and $\mathrm{pH}_{\mathrm{a}}$ rapidly returned to preexposure levels. At $30 \mathrm{~min}$ of $\mathrm{CO}_{2}$ exposure, animals were breathing slowly $(57 \pm 1.7$ breaths/min) and deeply, demonstrating moderate respiratory distress; however, maternal respiratory rate was not significantly changed until the recovery period, at which time it increased 2to 3 -fold to rates of 125 to 150 breaths $/ \mathrm{min}(p<0.001)$. Maternal respiratory rate returned to preexposure values within $90 \mathrm{~min}$ after ending $\mathrm{CO}_{2}$ exposure. Finally, maternal hematocrit increased significantly during $\mathrm{CO}_{2}$ exposure to $0.33 \pm 0.1$ (33 \pm $1.3 \% ; p<0.001$ ) but quickly returned to basal values during recovery.

Fetal arterial blood gas changes are illustrated in Figure 2. The alterations in fetal arterial blood gases followed a pattern similar to that seen in the ewe. That is, fetal $\mathrm{PaO}_{2}$ gradually rose during maternal oxygen exposure and was significantly elevated throughout the period of $\mathrm{O}_{2}$ plus $\mathrm{CO}_{2}$ exposure. As in the ewe,

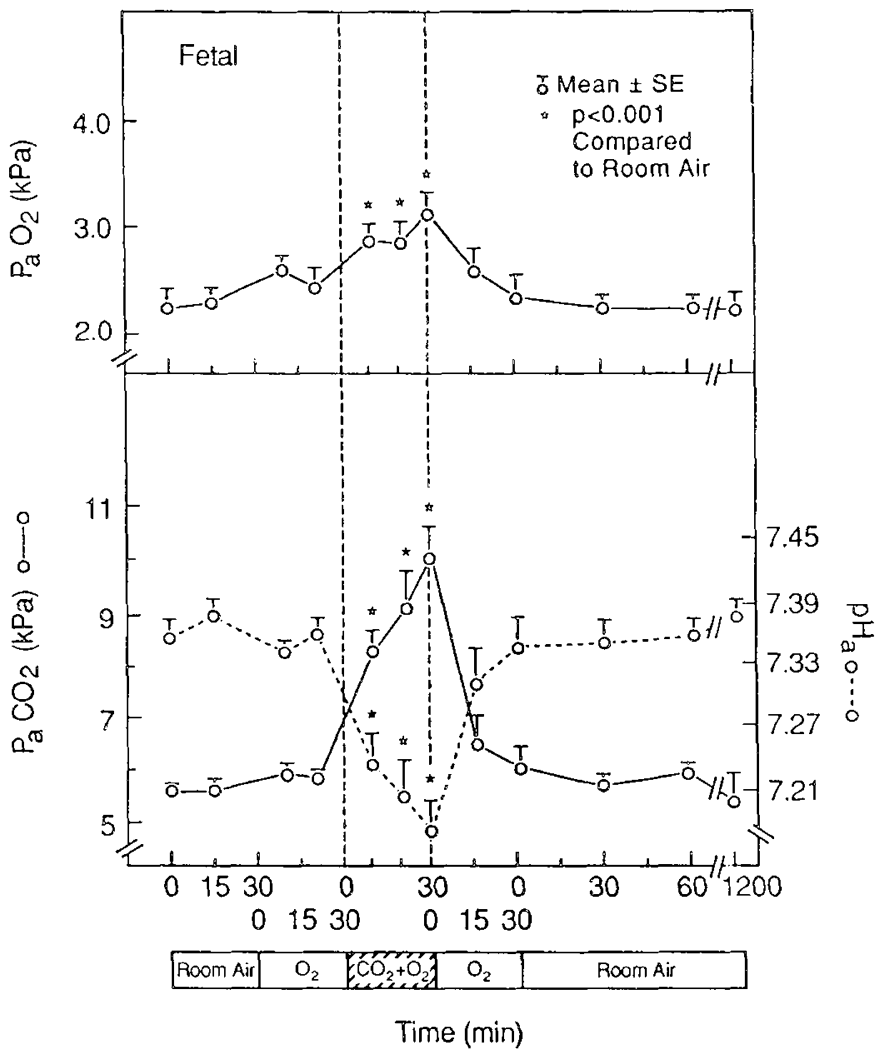

Fig. 2. Changes in fetal arterial blood gases and $\mathrm{pH}$ during successive gas exposures $(n=8)$. Analysis is by ANOVA.

respiratory acidosis rapidly developed during $\mathrm{CO}_{2}$ exposure, $\mathrm{PaCO}_{2}$ increasing to $10.0 \pm 0.61 \mathrm{kPa}(75 \pm 4.6 \mathrm{~mm} \mathrm{Hg})$ by 30 min of $\mathrm{CO}_{2}(p<0.001)$ and $\mathrm{pH}_{\mathrm{a}}$ decreasing to $7.16 \pm 0.04(p<$ 0.001 ); values during $\mathrm{CO}_{2}$ exposure were not different. After the $\mathrm{CO}_{2}$ was removed, $\mathrm{PaCO}_{2}$ and $\mathrm{pH}_{\mathrm{a}}$ rapidly returned to levels not different from control and remained unchanged thereafter. All blood gases were normal $20 \mathrm{~h}$ later. Fetal hematocrit was unchanged during and after $\mathrm{CO}_{2}$ exposure.

To further examine changes in the metabolic milieu, we measured plasma osmolality in maternal and fetal blood in four experiments. There were no alterations in either maternal or fetal plasma osmolality during the successive administration of these gas mixtures. Moreover, fetal plasma lactate was unchanged in two of these experiments, providing additional evidence that only respiratory acidosis had occurred.

Maternal and fetal cardiovascular responses. Control values for maternal and fetal cardiovascular measurements (Table 1) are similar to those previously reported $(11,13,19)$. Oxygen exposure had no significant effects on any variable (Figs. 3 and 4). However, during $\mathrm{CO}_{2}$ exposure, there was significant maternal tachycardia, which gradually resolved after ending $\mathrm{CO}_{2}$ exposure $(p<0.05)$, returning to baseline values $60 \mathrm{~min}$ later. MAP also 


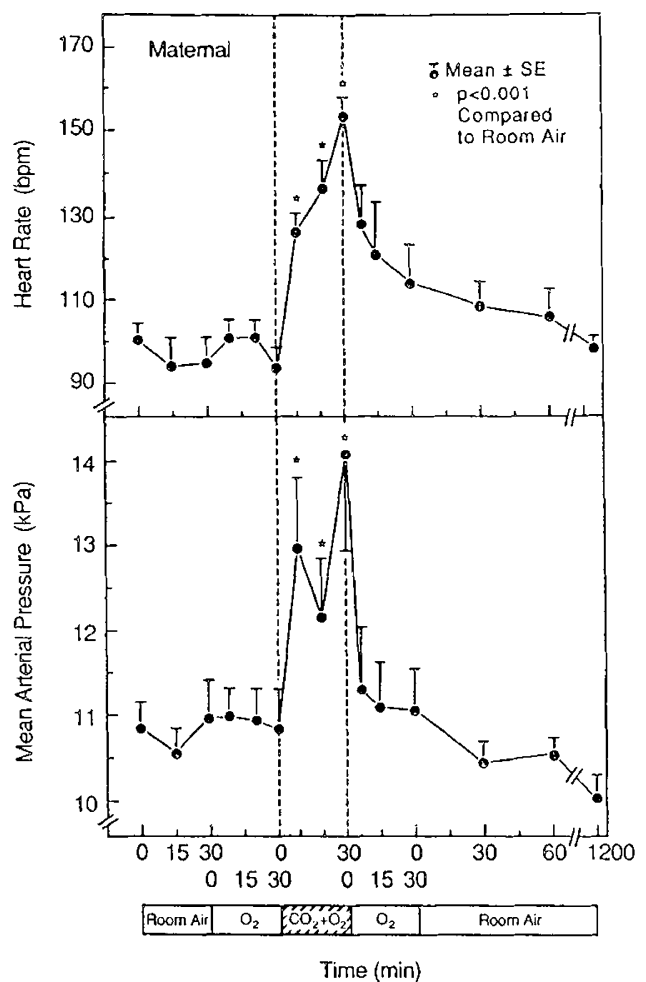

Fig. 3. Maternal cardiovascular changes during successive gas exposures $(n=8)$. Analysis is by ANOVA.

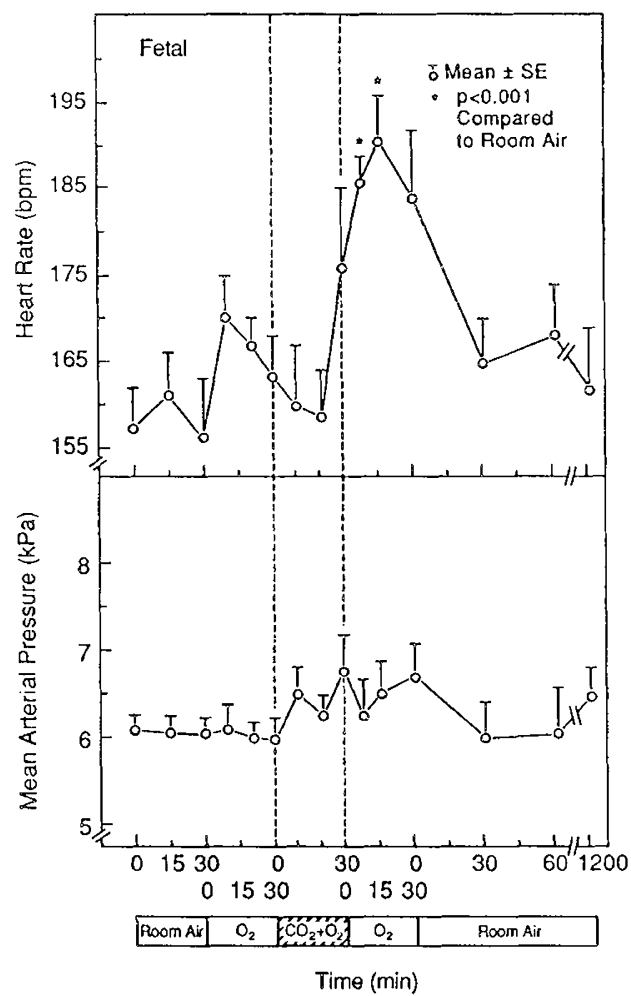

Fig. 4. Fetal cardiovascular changes during successive gas exposures $(n=8)$. Analysis is by ANOVA

increased and remained elevated during hypercapnia but returned to control levels more rapidly than heart rate, decreasing to basal values within $30 \mathrm{~min}$ after the exposure to $\mathrm{CO}_{2}$ was stopped. Despite these maternal hemodynamic responses, there were no significant changes in uterine blood flow in response to hypercapnia.
The fetal cardiovascular responses to hypercapnia are shown in Figure 4. In contrast to that observed in the ewe, fetal heart rate was unchanged during hypercapnia. However, toward the end of $\mathrm{CO}_{2}$ exposure, heart rate began to rise and, during the recovery period, there was development of significant tachycardia, which persisted during the second period of $\mathrm{O}_{2}$ exposure, gradually returning to control levels by $20 \mathrm{~h}$. The response in corrected fetal MAP was quite variable (Fig. 4); although there was a $20 \%$ increase in fetal MAP during and immediately after $\mathrm{CO}_{2}$ exposure, this was not statistically significant $(p>0.05$; ANOVA). Of note, amniotic fluid pressure increased from 0.80 \pm 0.33 to $1.47 \pm 0.44 \mathrm{kPa}(6.0 \pm 2.5$ to $11 \pm 3.3 \mathrm{~mm} \mathrm{Hg} ; p<$ $0.001)$ by $30 \mathrm{~min}$ of $\mathrm{CO}_{2}$ exposure and fell to $1.08 \pm 0.33 \mathrm{kPa}$ $(8.1 \pm 2.5 \mathrm{~mm} \mathrm{Hg})$ at $7.5 \mathrm{~min}$ postexposure, a value not different from control. This likely reflects the substantial maternal respiratory distress observed and increases in intraabdominal pressure rather than uterine contractions because uteroplacental blood flow was unaffected.

Plasma AVP. Plasma concentrations of maternal and fetal AVP before, during, and after $\mathrm{CO}_{2}$ exposure are presented in Table 2 and illustrated in Figure 5. Control values are similar to those previously reported by us for ewes or fetal sheep studied at a similar gestational age (13). Despite the presence of moderately severe hypercapnia, there were only modest and, interestingly, parallel alterations in maternal and fetal plasma AVP concentrations (Fig. 5), neither of which reached significance at any time point $(p=0.1)$, even by using a log transformation of the data to account for the variability seen.

Amniotic fluid levels of AVP were $48.5 \pm 7.7 \mathrm{pmol} / \mathrm{L}$ in the control period and were unchanged during the course of these studies $(p>0.05)$.

Plasma catecholamines. The pattern of change in plasma catecholamine concentrations during successive gas exposures is presented in Table 2. Maternal plasma concentrations of catecholamines were highly variable; therefore, we used the log values to analyze these data. Although there was a 3- to 4-fold increase in maternal $\mathrm{NE}$ and $\mathrm{E}$ levels between exposure to $\mathrm{O}_{2}$ alone and $\mathrm{O}_{2}$ plus $\mathrm{CO}_{2}$ exposure and a gradual return to baseline thereafter, these changes were not statistically significant ( $p>0.1$; ANOVA). Nonetheless, a significant, albeit a weak, relationship was observed between maternal $\mathrm{PaCO}_{2}$ and $\mathrm{NE}(r=0.37 ; p=0.006)$ and $\mathrm{PaCO}_{2}$ and $\mathrm{E}(r=0.53 ; p<0.001)$. There were also no significant changes in plasma dopamine.

The pattern of change in fetal plasma catecholamine levels was similar to that seen in the ewe. Again, there was marked variability and data were analyzed as noted above. Fetal plasma concentrations of dopamine and NE were not significantly changed. On the other hand, fetal plasma concentrations of $E$ increased 4-fold at $30 \mathrm{~min}$ of $\mathrm{CO}_{2}$ exposure $(p=0.01)$ compared with $\mathrm{O}_{2}$ alone; as in the ewe, levels gradually returned to values not different from control after the end of hypercapnia. When we examined the relationship between fetal $\mathrm{PaCO}_{2}$ and plasma catecholamines, there was a significant correlation only between $\mathrm{PaCO}_{2}$ and $\mathrm{E}(r=0.58 ; p<0.001)$.

\section{DISCUSSION}

Among mammals, different forms of stress result in increased secretion of AVP and catecholamines. In the fetus, hypoxemia (11), asphyxia $(8,10-12,15)$, hypotension (20), hemorrhage (21, $22)$, parturition $(12,23)$, cord occlusion (9), and increases in plasma osmolality (24) are potent stimuli resulting in substantial increases in plasma AVP concentrations. Although the effects of hypovolemia and hyperosmolality on hormone secretion are better understood, it is unclear how those stresses associated with changes in arterial blood gases and $\mathrm{pH}$ result in increased fetal AVP or catecholamine release. Nonetheless, "hypoxia" has been suggested as the primary stimulant. In view of this, we have attempted to elucidate the mechanisms responsible for AVP 
Table 2. Hormonal changes in pregnant ewes and their fetuses in response to oxygen and/or carbon dioxide inhalation $(n=8)^{*}$

\begin{tabular}{cccccc}
\hline & \multicolumn{5}{c}{ Inspired gas } \\
\cline { 4 - 6 } & $\begin{array}{c}\mathrm{RA} \dagger \\
(15 \mathrm{~min})\end{array}$ & $\begin{array}{c}\mathrm{O}_{2} \dagger \\
(20 \mathrm{~min})\end{array}$ & $\begin{array}{c}\mathrm{O}_{2}+\mathrm{CO}_{2} \dagger \\
(30 \mathrm{~min})\end{array}$ & $\begin{array}{c}\mathrm{O}_{2} \\
(30 \mathrm{~min})\end{array}$ & $\begin{array}{c}\mathrm{RA} \\
(60 \mathrm{~min})\end{array}$ \\
\hline Maternal & & & & \\
AVP (pmol/L) & $55.1 \pm 1.1$ & $48.2 \pm 8.2$ & $129 \pm 47$ & $63.0 \pm 18$ & $43.7 \pm 5.5$ \\
DA (nmol/L) & $0.37 \pm 0.16$ & $0.67 \pm 0.31$ & $0.49 \pm 0.08$ & $0.39 \pm 0.14$ & $0.67 \pm 0.16$ \\
NE (nmol/L) & $2.23 \pm 0.74$ & $2.77 \pm 0.82$ & $8.52 \pm 3.97$ & $6.88 \pm 2.28$ & $3.42 \pm 0.69$ \\
E (nmol/L) & $0.56 \pm 0.15$ & $0.88 \pm 0.43$ & $3.36 \pm 2.45$ & $0.51 \pm 0.28$ & $0.55 \pm 0.10$ \\
Fetal & & & & \\
AVP (pmol/L) & $41.9 \pm 7.1$ & $46.2 \pm 7.7$ & $137 \pm 63$ & $101 \pm 35$ & $46.9 \pm 6.4$ \\
DA (nmol/L) & $0.37 \pm 0.14$ & $0.53 \pm 0.18$ & $0.91 \pm 0.14$ & $0.67 \pm 0.14$ & $0.75 \pm 0.22$ \\
NE (nmol/L) & $3.23 \pm 0.33$ & $5.12 \pm 2.61$ & $12.4 \pm 3.89$ & $4.36 \pm 1.07$ & $7.96 \pm 3.19$ \\
E (nmol/L) & $0.27 \pm 0.10$ & $0.55 \pm 0.16$ & $2.27 \pm 0.90 \pm$ & $0.62 \pm 0.17$ & $0.32 \pm 0.60$ \\
\hline
\end{tabular}

*Values presented are means \pm SEM.

$\dagger \mathrm{RA}$ represents room air or fraction of inspired oxygen $=0.21 ; \mathrm{O}_{2}$ represents fraction of inspired oxygen $=0.30 ; \mathrm{CO}_{2}$ represents fraction of inspired carbon dioxide $=0.10 ;$ DA, dopamine.

$\ddagger p=0.01$ compared with control.

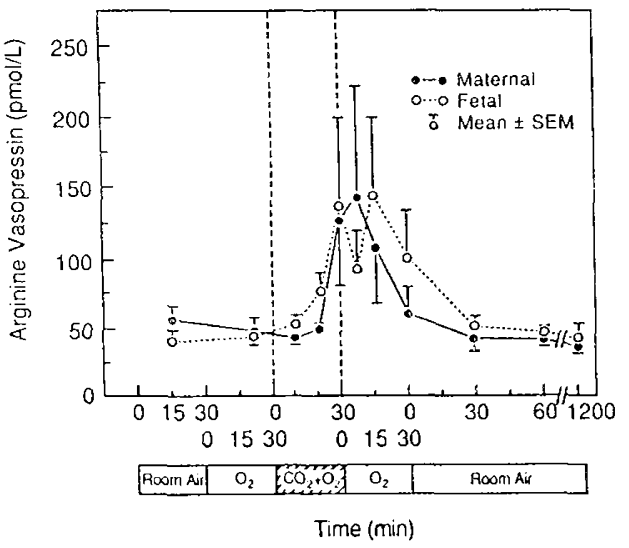

Fig. 5. The effects of hyperoxic hypercapnia on maternal and fetal plasma concentrations of AVP $(n=8)$.

release in response to asphyxia/hypoxemia by examining each of the components of an asphyxial episode (11, 13).

During acute asphyxia, i.e. the simultaneous occurrence of hypoxemia, acidosis, and hypercapnia, we and others have reported a 40 - to 240 -fold rise in ovine fetal plasma AVP $(5,8-$ 12). In contrast, exposure to hypoxemia $\left[\mathrm{PaO}_{2}\right.$ as low as $1.47 \mathrm{kPa}$ $(11 \mathrm{~mm} \mathrm{Hg})]$ in the absence of either metabolic acidosis or hypercapnia (i.e. respiratory acidosis) results in relatively small increases in plasma AVP (11). Because this suggested that hypoxemia alone may not be the major determinant of AVP release during asphyxia, we examined the role of acute metabolic acidemia in the release of this peptide hormone in fetal sheep of similar gestational ages (13). In those studies, $\mathrm{NH}_{4} \mathrm{Cl}$ infusion resulted in a fall in fetal arterial $\mathrm{pH}$ to $7.04 \pm 0.05$, but only a 2fold rise in plasma AVP concentration, which was not related to the fall in $\mathrm{pH}$. Thus, it was evident from these studies that neither severe metabolic acidosis nor a $45 \%$ fall in $\mathrm{PaO}_{2}$ was solely responsible for the marked increases in plasma AVP reported to occur during acute fetal asphyxia.

In the studies presented here, we sought to determine the role of acute hypercapnia and respiratory acidosis in the fetal secretion of AVP. Although this has been examined in adult animals $(4,25,26)$, it has not been studied in the fetus. In preliminary studies, ewes frequently developed hypoxemia and metabolic acidosis during acute hypercapnia; therefore, we chose to maintain oxygenation by providing $30 \%$ inspired $\mathrm{O}_{2}$. In these studies, oxygen exposure had no effect on maternal or fetal cardiovascular or hormonal parameters. Maternal and fetal hypercapnia occurred simultaneously and within $10 \mathrm{~min}$ of maternal exposure to $30 \% \mathrm{O}_{2}$ plus $10 \% \mathrm{CO}_{2}$, resulting in the development of persistent and significant respiratory acidosis in the absence of either hypoxia or metabolic acidosis. However, the gradual rise in maternal and fetal plasma concentrations of AVP did reach significance over a broad range of hypercapnia, i.e. up to 10.7 $\mathrm{kPa}(80 \mathrm{~mm} \mathrm{Hg})$. Our observations in the ewe are consistent with those of Raff et al. (25), who, in studies of normoxic hypercapnia in anesthetized adult dogs, achieved values for $\mathrm{PaCO}_{2}$ and $\mathrm{pH}_{\mathrm{a}}$ similar to those observed by us in the unanesthetized pregnant ewe. Thus, similar mechanisms for AVP secretion may be at work in the mother and fetus. It is noteworthy that, in the adult, Raff et al. (3) also observed no change in plasma AVP during normocapnic hypoxia $\left[\mathrm{PaO}_{2} \simeq 5.33 \mathrm{kPa}(40 \mathrm{~mm} \mathrm{Hg})\right]$, an observation consistent with our studies in the unrestrained, unanesthetized ewe and fetus (11).

In the studies presented here, we examined other variables that might affect AVP secretion, including uteroplacental blood flow, and none of these factors was significantly altered. For example, decreases in $\mathrm{O}_{2}$, alterations in plasma osmolality, and decreases in MAP did not occur. Stimulation of the peripheral chemoreceptors has also been shown to increase AVP secretion in the adult (26). Although maternal carotid chemoreceptors were obviously stimulated, as evidenced by the $50 \%$ rise in heart rate, the modest rise in plasma AVP was not significant. It may be that the simultaneous rise in maternal MAP acted to attenuate maternal AVP secretion, as suggested by several investigators ( 2 , $3,26)$, thereby resulting in nonsignificant increases. This is supported by the achievement of maximum maternal AVP levels after $\mathrm{CO}_{2}$ exposure when MAP had returned to control levels. A similar series of events may have occurred in the fetus, because plasma AVP also did not attain maximum values until the end of $\mathrm{CO}_{2}$ exposure, when fetal heart rate was significantly elevated. In contrast to that in the mother, the rise in fetal MAP was modest $(\sim 20 \%)$ and was not significant after correction for changes in amniotic sac pressure. Thus, the potential inhibitory effect of fetal MAP on AVP secretion is unclear. Moreover, the effects of increases in fetal MAP and chemoreceptor stimulation on AVP secretion have not been studied. Atrial natriuretic peptide has also been shown to attenuate or inhibit AVP secretion in the adult (27-29). We recently reported that increases in fetal MAP will cause substantial increases in right atrial pressure and the secretion of atrial natriuretic peptide (30). Therefore, it is possible that this series of events would inhibit or attenuate AVP secretion in both the ewe and fetus. Further studies are necessary to prove this.

Catecholamines are also released during asphyxia $(2,14)$. In the studies presented here, both NE and E were secreted by the pregnant ewe during hypercapnia, although this was quite variable. Furthermore, the relative increases in both catecholamines were similar, 2- to 3-fold, suggesting that the primary source of 


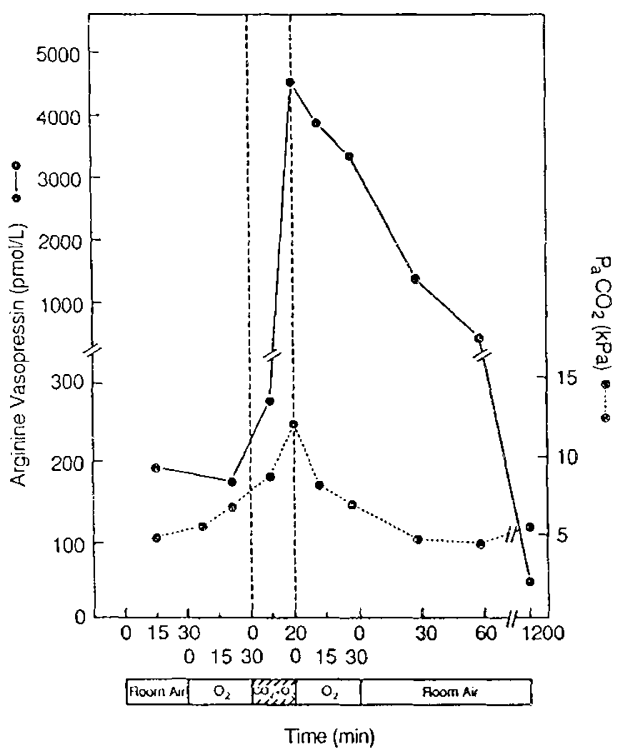

Fig. 6. The effect of marked hypercapnia on fetal secretion of AVP during a fall in arterial oxygen content.

maternal catecholamines might be the sympathetic nerve terminals as well as the adrenal medulla-conclusions similar to those obtained in adult dogs (14). In the fetus, NE and E also increased during hypercapnia, but only the latter reached significance, and both gradually fell after ending $\mathrm{CO}_{2}$ exposure. In contrast to that seen in the ewe, the relative rise in $E$ was more than 2 -fold greater than that of NE, 316 versus $142 \%$, suggesting that during fetal hypercapnia the predominant source of catecholamines is the adrenal medulla, a conclusion consistent with the observations of others (7). The differences between the adult and fetal animals in their levels and distribution of catecholamines may thus be explained on the basis of the relative contribution to the circulating pool of catecholamines from these two sources. The observations presented here suggest that the primary fetal and maternal hormonal response to the degree of hypercapnia experienced is the increased release of catecholamines, particularly $\mathrm{E}$, rather than AVP.

It is noteworthy that fetal and maternal plasma levels of catecholamines increased maximally during $\mathrm{CO}_{2}$ exposure, whereas the maximum rise in plasma concentrations of AVP was not attained until the end, or soon after the end, of $\mathrm{CO}_{2}$ exposure. Thus, the observed rise in MAP likely reflects the effects of the catecholamines or another pressor agent rather than those of AVP. This would also explain the cardiovascular responses previously seen during acute fetal hypoxemia (11), where the increase in fetal MAP also occurred before the rise in plasma levels of AVP. That more than one agent is associated with the fetal cardiovascular responses to hypoxemia or stresses has been suggested by others $(31,32)$. It also is possible that the earlier increase in catecholamine secretion might be responsible in part for the subsequent rise in plasma AVP levels. This is supported by in vivo and in vitro studies of the adult, in which catecholamines have been shown to modulate AVP secretion (33). Moreover, neurohistochemical studies of adult tissues have clearly established that the magnocellular neurons are surrounded by catecholamine-containing varicosities, especially NE (34). Thus, the relatively "late" and possibly attenuated rise in plasma AVP in the mother and fetus, although nonsignificant, might reflect the effect of catecholamine simulation rather than that of hypercapnia. In contrast, Block et al. (35) have suggested that in fetal sheep $\alpha_{1}$-adrenergic stimulation may serve to inhibit AVP secretion. Alternatively, both fetal and maternal AVP responses to hypercapnia may be slow as compared with catecholamine secretion.

In the adult, Raff et al. (25) have reported that synergism may exist between the different components of asphyxia in the secretion of AVP. It is noteworthy that, in a preliminary experiment (Fig. 6) in which $\mathrm{PaCO}_{2}$ increased from 5.33 to $12.0 \mathrm{kPa}$ (40 to $90 \mathrm{~mm} \mathrm{Hg}$ ) and $\mathrm{O}_{2}$ content fell from 9.8 to 5.7 vol\%, plasma AVP levels rose to $4550 \mathrm{pmol} / \mathrm{L}$, a value 40 -fold greater than that seen in this study, where oxygenation was maintained. This observation can be extrapolated to suggest that oxygen delivery to the neurohypophysis, measured as the product of blood flow times $\mathrm{O}_{2}$ content, determines if there is substantial tissue hypoxia/asphyxia and thus AVP release. Although $\mathrm{PaO}_{2}$ was maintained, this probably reflects a shift in the oxygen dissociation curve due to the changes in $\mathrm{pH}_{4}$ and $\mathrm{PaCO}_{2}$. This animal, therefore, demonstrates that asphyxia, i.e. simultaneous alterations in $\mathrm{CO}_{2}, \mathrm{O}_{2}$, and $\mathrm{pH}$, may be important in fetal AVP release and that synergism likely occurs in vivo. The minimal effects of each asphyxial component seen in this and earlier studies $(11,13)$ suggest that responses to asphyxia reflect a complex phenomenon, resulting in the release of local factors that act on the magnocellular neurons, potentially releasing other yet unidentified circulating vasopressinergic substances or stimulating the CNS directly.

Acknowledgments. The authors thank Sonnya Coultrup and Denise Doherty for excellent technical assistance, Susan Battle for valuable secretarial assistance, and Drs. R. Weitzman and D. Fisher for the antiserum to AVP.

\section{REFERENCES}

1. Kochler RC, McDonald BW, Krasney JA 1980 Influence of $\mathrm{CO}_{2}$ on cardiovascular response to hypoxia in conscious dogs. Am J Physiol 239:H545H558

2. Nahas GG, Ligou JC. Mehlman B 1960 Effects of $\mathrm{pH}$ changes on $\mathrm{O}_{2}$ uptakc and plasma catecholamine levels in the dog. Am J Physiol 198:60-66

3. Raff H. Shinsako J, Keil LC, Dallman MF 1983 Vasopressin. ACTH, and blood pressure during hypoxia induced at different rates. Am J Physiol 245:E489-E493

4. Rose Jr CE, Anderson RJ. Carey RM 1984 Antidiuresis and vasopressin releasc with hypoxemia and hypercapnia in conscious dogs. Am J Physiol 247:R127-R134

5. Rurak DW 1978 Plasma vasopressin levels during hypoxaemia and the cardiovascular effects of exogenous vasopressin in foetal and adult sheep. J Physiol $277: 341-357$

6. Sechzer PH, Egbert LD, Linde HW, Cooper DY, Dripps KD, Price HL 1960 Effect of $\mathrm{CO}_{2}$ inhalation on arterial pressure, ECG and plasma catecholamines and 17-OH corticosteroids in normal man. J Appl Physiol 15:454458

7. Dawes GS, Lewis BV, Milligan JE, Roach MR. Talner NS 1968 Vasomotor responses in the hind limbs of foetal and new-born lambs to asphyxia and aortic chemoreceptor stimulation. J Physiol 195:55-81

8. Alexander DP Forsling ML Martin MJ Nixon DA, Ratcliffe JG Redstone D Tunbridge D 1972 The effect of maternal hypoxia on fetal pituitary hormone release in the sheep. Biol Neonate 21:219-228

9. Daniel SS, Husain ML, Milliez J, Stark RI, Yeh MN, James LS 1978 Rena response of fetal lamb to complete occlusion of umbilical cord. Am J Obste Gynecol 131:514-519

10. Daniel SS, Stark RI, Zubrow AB, Fox HE, Husain MK, James LS 1983 Factor in the release of vasopressin by the hypoxic fetus. Endocrinology 113:16231628

11. DeVane GW. Naden RP. Porter JC, Rosenfeld CR 1982 Mechanism of arginine vasopressin release in the sheep fetus. Pediatr Res 16:504-507

12. Stark RI. Daniel SS, Husain KM. James LS, Vande Wicle RL 1979 Arginine vasopressin during gestation and parturition in sheep fetus. Biol Neonate 25:235-241

13. Faucher DJ, Lowe TW, Magness RR, Laptook AR, Porter JC, Rosenfeld CR 1987 Vasopressin and catecholamine secretion during metabolic acidemia in the ovine fetus. Pediatr Res 21:38-43

14. Rose Jr CE, Althaus JA, Kaiser DL, Miller ED, Carey RM 1983 Acute hypoxemia and hypercapnia: increase in plasma catecholamines in conscious dogs. Am J Physiol 245:H924-H929

15. Rosenfeld CR, Worley RJ, Milewich L, Gant Jr NF, Parker Jr CR 1980 Ovine feto-placental sulfoconjugation and aromatization of dehydrocpiandrosterone. Endocrinology 106:1971-1979

16. Skowsky WR, Rosenbloom AA. Fisher DA 1974 Radioimmunoassay measurement of arginine vasopressin in serum: development and application. J Clin Endocrinol Metab 38:278-287

17. Crofton JT. Share L, Wang BC. Shade RE 1980 Pressor responses to vasopres $\sin$ in the rat with DOC-salt hypertension. Hypertension 2:424-431

18. Ben-Jonathan N. Porter JC 1976 A sensitive radioenzymatic assay for dopa- 
mine, norepinephrine, and epinephrine in plasma and tissue. Endocrinology 98:1497-1507

19. Faucher DJ, Laptook AR. Parker Jr CR, Porter JC, Rosenfeld CR 1988 Increased fetal secretion of ACTH and cortisol by arginine vasopressin. Am J Physiol 254:R410-R416

20. Rose JC, Meis PJ, Morris M 1981 Ontogeny of endocrine (ACTH, vasopressin, cortisol) responses to hypotension in lamb fetuses. Am J Physiol 240:E656E661

21. Alexander DP. Britton HG. Forsling ML, Nixon DA, Ratcliffe JG 1974 Pituitary and plasma concentrations of adrenocorticotrophin, growth hormone, vasopressin and oxytocin in fetal and maternal sheep during the latter half of gestation and the response to haemorrhage. Biol Neonate 24:206219

22. Drummond WH, Rudolph AM, Keil LC, Gluckman PD, MacDonald AA, Heymann MA 1980 Arginine vasopressin and prolactin after hemorrhage in the fetal lamb. Am J Physiol 238:E214-E219

23. DeVane GW, Porter JC 1980 An apparent stress-induced release of arginine vasopressin by human neonates. J Clin Endocrinol Mctab 51:1412-1416

24. Weitzman RE, Fisher DA, Robillard J, Erenberg A, Kennedy R, Smith F 1978 Arginine vasopressin response to an osmotic stimulus in the fetal sheep. Pediatr Res 12:35-38

25. Raff H, Shinsako J, Keil LC, Dallman MF 1983 Vasporessin, ACTH, and corticosteroids during hypercapnia and graded hypoxia in dogs. Am J Physio 244:E453-E458

26. Share L, Levy MN 1966 Effect of carotid chemoreceptor stimulation on plasma antidiuretic hormone titer. Am J Physiol 210:157-161
27. Fujio N, Ohashi M, Nawata $H$, Kato K, Ibayashi $H$, Kangawa K, Matsuo $H$ $1986 \alpha$-Human atrial natriurctic polypeptide reduces the plasma arginine vasopressin concentration in human subjects. Clin Endocrinol (Oxf) 25:181187

28. Samson WK 1985 Atrial natriuretic factor inhibits dehydration and hemorrhage-induced vasopressin release. Neuroendocrinology 40:277-279

29. Williams TDM, Walsh KP, Pitts E, Sutton R, Lightman SL 1988 Rebound increase in plasma renin and vasopressin following graded infusions of atrial naturetic peptide in man. J Endocrinol lnvest 11:31-35

30. Rosenfeld CR, Samson WK, Roy TA, Faucher DJ, Magness RR 1988 Effect of vasopressors on fetal relcase of atrial natriuretic peptide (ANP). Pediatr Res 23:224A(abstr)

31. Reuss ML, Parer JT, Harris JL. Krueger TR 1982 Hemodynamic effects of alpha-adrenergic blockade during hypoxia in fetal sheep. Am $\mathrm{J}$ Obstet Gynecol 142:410 -415

32. Perez R, Espinoza M, Riquelme R, Parer JT, Llanos AJ 1989 Arginine vasopressin mediates cardiovascular responses to hypoxemia in fetal sheep. Am J Physiol 256:R1011-R1018

33. Sklar AH, Schrier RW 1983 Central nervous system mediators of vasopressin release. Physiol Rev 63:1243-1280

34. Sladek JR. McNeil TH, Khachaturian H, Zimmerman EA 1980 Chemical neuroanatomy of monoamine-neuropeptide interactions in the hypothalamic magnocellular system. In: Yoshida S, Share L, Yagi K (eds) Antidiuretic amic magnocellular system. In: Yoshida S, Share L, Yagi
Hormone. University Park Press, Baltimore, pp $1-17$

35. Block SM, Rose JC, Ray D, Rawashdeh N, Barnes KD 1988 Endocrine responses of fetal lambs to hemorrhage after $\alpha_{1}$-adrenergic receptor blockade Am J Obstet Gynecol 159:1256-1262 